\title{
Increased inflammation and intracellular calcium caused by ultrafine carbon black is independent of transition metals or other soluble components
}

\author{
D M Brown, V Stone, P Findlay, W MacNee, K Donaldson
}

\begin{abstract}
Objectives-Particulate air pollution has been shown to cause adverse health effects, and the ultrafine particle component has been implicated. The aim of the present study was to investigate whether an ultrafine particle exerted its effects through transition metals or other soluble factors released from the surface of the particles.
\end{abstract}

Methods-Both in vitro and in vivo models were used to test the imflammogenicity of carbon black (CB) and ultrafine carbon black (UfCB) and the role of transition metals was investigated by treating the particles with desferrioxamine mesylate (desferal), a transition metal chelator. Rats were instilled with particles and the cell population assessed by bronchoalveolar lavage (BAL). Calcium homeostasis in macrophages was assessed with a fluorimetric technique.

Results-UfCB was inflammogenic compared with $C B$ when instilled into Wistar rat lungs, an effect which could not be ameliorated by desferal treatment of the particles. Particle leachates produced no significant inflammation in vivo. In vitro experiments showed that the cytosolic calcium ion concentration in Mono Mac 6 cells was increased significantly after UfCB treatment and treatment of particles with desferal did not alter these effects. Particle leachates had no effect on cytosolic calcium ion concentration. Iron was not detected in leachates of the particles with the desferal assay, however, $\mathrm{ng} / \mathrm{mg}$ of particles were detectable in citrate leachates with inductively coupled plasma-mass spectrometry (ICP-MS). Conclusions-The increased inflammogenicity of UfCB compared with CB cannot be explained by soluble transition metals released from or by accumulation of iron at the particle surface. Differences may be accounted for by increased surface area or particle number.

(Occup Environ Med 2000;57:685-691)

Keywords: ultrafine; calcium; transition metals

There has been growing interest in the pulmonary response to small diameter particles with regard to their role in the adverse health effects of particulate air pollution. ${ }^{1}$ Ultrafine particles have been shown to have marked toxicity, ${ }^{2}$ and it has been hypothesised that the ultrafine component of particulate air pollution $\left(\mathrm{PM}_{10}\right)$ is responsible for their adverse effects. ${ }^{23}$ The precise mechanisms whereby ultrafine particles exert their effects in the lung are not fully understood. ${ }^{2}$ In long term high dose inhalation studies in animals, the chronic effects produced by ultrafine particles include inflammation, increased chemokine expression, epithelial hyperplasia, pulmonary fibrosis, and lung tumours. ${ }^{4-8}$ However, these effects are a consequence of overload. ${ }^{9}$ Short term low dose nonoverloaded inhalation exposure to ultrafine carbon black (UfCB) has produced mild inflammation, oxidant stress, and modulation of the coagulation system in normal rats. ${ }^{10}$

An important part of the ultrafine hypothesis is to dissect out whether the ultrafine habit is itself inflammogenic or whether ultrafine particles simply provide a large surface area for transition metals to be released. Samples of environmental particulate - such as residual oil fly ash (ROFA) ${ }^{11}$ and Provo $\mathrm{PM}_{10}{ }^{12}$ - have been shown to cause inflammation by mechanisms mediated by transition metals - that is, a soluble preparation of the particles contains all the proinflammatory activity. We have also shown that soluble components of $\mathrm{PM}_{10}$ that can be chelated - that is, transition metals - are the source of oxidative stress in $\mathrm{PM}_{10}{ }^{13}$ To understand what the relative toxic potency of the components of $\mathrm{PM}_{10}$ are it is necessary to know the toxicity of the individual components. We have used fine carbon black (CB) and UfCB to answer the question "can ultrafine particles cause toxicity independently of soluble transition metals?" The importance of showing whether ultrafine particles cause toxicity through mechanisms other than transition metals lies in a better understanding of the total hazard associated with any $\mathrm{PM}_{10}$ sample. If ultrafine particles could be shown to have effects through other mechanisms than by transition metal then simply measuring the transition metals does not describe the potential toxicity. We therefore used UfCB as a model ultrafine particle and set out to find whether transition metals had any role in its ability to cause increased inflammation in rat lungs and proinflammatory effects in vitro.

Therefore, the aim of the present study was to elaborate the role of transition metals in the proinflammogenic effect of UfCB with both in vitro and in vivo models. In the in vivo model, particles were instilled into the lungs of rats and the number of neutrophils was assessed by bronchoalveolar lavage, as a measure of inflammation. We used the transition metal chelator desferrioxamine and also used leachates of the soluble component, which would 
contain any transition metals, to investigate the role of transition metals in the proinflammatory effects of UfCB. The in vitro model is one where we have previously shown a greater effect of UfCB than $\mathrm{CB}$ on the cytosolic calcium ion concentration. ${ }^{22}$ The $\mathrm{Ca}^{2+}$ system is an important signalling pathway for the activation of the proinflammatory transcription factor $\mathrm{NF}-\kappa \mathrm{B}$ and other proinflammatory transcription factors which are regulated through several second messengers. ${ }^{15} \mathrm{Ca}^{2+}$ is stored in the endoplasmic reticulum (ER), from where it is released on stimulation of the cell. $\mathrm{Ca}^{2+}$ release from the ER leads to the activation of calcium ion influx across the plasma membrane through calcium channels. Changes in calcium ion flux within the cell have been shown with different pathogenic particles ${ }^{16} 17$ which suggests a role for calcium homeostasis in the proinflammatory effects of particles.

\section{Materials and methods}

PARTICLE CHARACTERISTICS

Fine carbon black was obtained from $\mathrm{H}$ Haeffner, Chepstow, UK (Huber 900) and UfCB obtained from Degussa (Printex 90). The average particle size of the two types of particle were $320 \mathrm{~nm}$ for CB and $14 \mathrm{~nm}$ for UfCB.

PREPARATION OF PARTICLE LEACHATES

The CB and UfCB were suspended in citrate phosphate buffer $\mathrm{pH} 4.6$ and 7.2 at a mass concentration of $10 \mathrm{mg} / \mathrm{ml}$. All buffers and reagents were made up in chelex treated water. The particle suspensions were sonicated for 2 minutes to aid dispersion and mixed on a rotary mixer for 24 hours at $37^{\circ} \mathrm{C}$. After incubation, the suspensions were transferred to 50 $\mathrm{ml}$ centrifuge tubes and spun at $145 \mathrm{~g}$ for 20 minutes. Leachates were pipetted into clean tubes and filtered through $0.22 \mu \mathrm{m}$ filters. The $\mathrm{Fe}^{3+}$ concentration in each leachate was estimated as outlined below.

A second series of particle leachates were prepared as before in saline and $\mathrm{pH} 7.2$ citrate buffer at a concentration of $2 \mathrm{mg} / \mathrm{ml}$ for use in in vivo experiments. Leachates were prepared immediately before instillation into rat lungs.

\section{PREPARATION OF PARTICLE LEACHATES FOR} ELEMENTAL ANALYSIS

Particles were suspended in saline or citrate buffer $\mathrm{pH} 7.2$ at a concentration of $1 \mathrm{mg} / \mathrm{ml}$, sonicated to disperse the particles and incubated for 24 hours at $37^{\circ} \mathrm{C}$. Particle suspensions were then centrifuged at $145 \mathrm{~g}$, and the supernatant was collected and filtered through $0.22 \mu \mathrm{m}$ filters. Each filtered sample was diluted 1/50 with chelex treated water and analysed with inductively coupled plasma-mass spectrometry (ICP-MS).

DESFERRIOXAMINE TREATMENT OF PARTICLES The CB and UfCB were suspended in either chelex treated water or $10 \mathrm{mM}$ desferrioxamine mesylate (desferal, Sigma, Poole, Dorset, UK) at a particle mass concentration of 1 $\mathrm{mg} / \mathrm{ml}$ and incubated in a shaking water bath for 2 hours at $37^{\circ} \mathrm{C}$. After incubation, samples were centrifuged at $145 \mathrm{~g}$, the supernatant was removed, and the particles washed twice with saline. Finally the particles were resuspended in saline at a concentration of $1 \mathrm{mg} / \mathrm{ml}$.

PARTICLE AND PARTICLE LEACHATE INSTILLATION Female Sprague Dawley rats about 4 months old were used in all studies. The animals were anaesthetised with halothane, cannulated with a laryngoscope to expose the trachea and 0.5 $\mathrm{ml}$ of a $1 \mathrm{mg} / \mathrm{ml}$ particle suspension contained in saline instilled into the lungs. A separate group of animals received $0.5 \mathrm{ml}$ appropriate particle leachate. All animals were conscious within minutes of this procedure and suffered no ill effects. Treated animals were killed after 24 hours.

BRONCHOALVEOLAR LAVAGE

Rats were killed with a single intraperitoneal injection of pentobarbital, and the lungs were cannulated, removed, and lavaged with $4 \times 8 \mathrm{ml}$ volumes of sterile saline. The first lavage was retained in a separate tube for lactate dehydrogenase $(\mathrm{LDH})$ and protein estimations. Untreated rats were lavaged to provide bronchoalveolar lavage (BAL) which was used in the experiments outlined later. Tubes were spun at $100 \mathrm{~g}$ for 5 minutes at $4^{\circ} \mathrm{C}$, the supernatant was removed, the cell pellet from the first lavage was combined with the cells from the same lavage and resuspended in $1 \mathrm{ml}$ phosphate buffered saline (PBS). Total cells were counted, cytocentrifuge smears were prepared for differential cell counts, and stained with Diffquick (Raymond A Lamb, London). Three hundred cells per slide were counted and the results expressed as the total number of neutrophils in the lung lavage.

TREATMENT OF PARTICLES WITH BAL AND BSA A stock solution of bovine serum albumin (BSA, $0.5 \mathrm{mg} / \mathrm{ml}$ in saline) was prepared. The UfCB particles were suspended at concentrations ranging from $0.3-5 \mathrm{mg} / \mathrm{ml}$ in this solution and in BAL from control rats, and were briefly sonicated and incubated in a shaking water bath at $37^{\circ} \mathrm{C}$ for 1 hour. Samples were centrifuged at $145 \mathrm{~g}$ for 10 minutes and the supernatants were removed for protein estimations.

MEASUREMENT OF Fe(III)

The amount of $\mathrm{Fe}$ (III) released from the particles and combining with desferal at $\mathrm{pH} 4.6$ and pH 7.2 was measured spectrophotometrically by comparison with a standard curve of $\mathrm{FeCl}_{3}$. One hundred microlitres of sample or standard were added to triplicate groups of wells on a 96 well plate and $100 \mu 12 \mathrm{mM}$ desferal was added to each well. The plate was immediately read on a Dynatec plate reader at $430 \mathrm{~nm}$. Standards consisted of a range of concentrations of $\mathrm{FeCl}_{3}$ from 15.625 to $1000 \mu \mathrm{M}$ diluted in buffer at the appropriate $\mathrm{pH}$.

\section{PROTEIN ASSAY}

Biorad stock reagent was diluted $1 / 5$ with distilled water and filtered. Two hundred microlitres of diluted reagent were pipetted into wells on a 96 well plate, triplicate groups 
per test and per sample. Five microlitres of sample were then added to the appropriate well, mixed, and incubated at room temperature for 15 minutes before reading on a plate reader at $450 \mathrm{~nm}$. Standards consisted of BSA solutions ranging from 1 to $0.0625 \mathrm{mg} / \mathrm{ml}$.

LACTATE DEHYDROGENASE ASSAY

Fifty microlitres of $0.75 \mathrm{mM}$ aqueous sodium pyruvate (Sigma) solution containing NADH (Sigma) at a concentration of $1 \mathrm{mg} / \mathrm{ml}$ were pipetted into each well of a 96 well plate and incubated at $37^{\circ} \mathrm{C}$ for 5 minutes. A series of standards were prepared to give a range of dilutions representing 0-2000 Units $/ \mathrm{LDH} / \mathrm{ml}$. Fifty microlitres of pyruvate/NADH solution gave a concentration of $2000 \mathrm{LDH}$ Units $/ \mathrm{ml}$. Ten microlitres of test sample or appropriate standard were added to each well in triplicate groups and thoroughly mixed. The plate was incubated for exactly 30 minutes at $37^{\circ} \mathrm{C}$. Fifty microlitres of 2,4-dinitrophenylhydrazine (Sigma) solution dissolved in $1 \mathrm{M} \mathrm{HCl}$ were added to each well and incubated at room temperature for 20 minutes. To develop the final colour, $50 \mu \mathrm{l} 4 \mathrm{M} \mathrm{NaOH}$ were added to each well, the plate was mixed and allowed to stand for 5 minutes. The plate was read at $540 \mathrm{~nm}$ on an automatic plate reader.

\section{CALCIUM MEASUREMENTS}

Mono Mac 6 (MM6) cells were grown in continuous culture in RPMI medium (Sigma) containing $1 \mathrm{mM}$ sodium pyruvate, $1 \mathrm{mM}$ oxaloacetate, $1 \mu \mathrm{g} / \mathrm{ml}$ holotransferrin, nonessential amino acids, L-glutamine, penicillin/ streptomycin, and $20 \%$ foetal calf serum (all Sigma). Cells were adjusted to $4 \times 10^{6} \mathrm{cells} / \mathrm{ml}$, and centrifuged at $145 \mathrm{~g}$ for 2 minutes. The medium was removed, and the cells resuspended in $1 \mathrm{ml}$ PBS and transferred to an Eppendorf tube. The tube was centrifuged at $145 \mathrm{~g}$ for 2 minutes at $4^{\circ} \mathrm{C}$, PBS was removed and the cells were resuspended in serum free Roswell Park Memorial Institute (RPMI) medium containing $23 \mathrm{mM}$ Hepes buffer. Cells were loaded with $1 \mu \mathrm{g} / \mu \mathrm{l}$ Fura 2 AM (Sigma) in dimethyl sulfoxide (DMSO, $2 \mu \mathrm{l} / \mathrm{ml}$ cell suspension), the tube was wrapped in foil and incubated in a shaking water bath for 20 minutes at $34^{\circ} \mathrm{C}$. After incubation, the tube was centrifuged at $145 \mathrm{~g}$ for 2 minutes at $4^{\circ} \mathrm{C}$, the medium was removed and replaced with $1.5 \mathrm{ml}$ fresh serum free RPMI medium.

The Fura 2 AM loaded cells were transferred to a quartz cuvette containing a magnetic stirrer, placed immediately into a fluorimeter with heated block and basal fluorescence measurements obtained over 500 seconds. The fluorimeter was set up to give excitation wavelengths of $340 \mathrm{~nm}$ and $380 \mathrm{~nm}$, emission $510 \mathrm{~nm}$, and excitation and emission slit widths set at $5 \mathrm{~nm}$. During the experiments, the cuvette temperature was kept constant at $37^{\circ} \mathrm{C}$. Continuous readings were recorded at 1 second intervals. After 500 seconds, $100 \mu \mathrm{l}$ appropriate treatment in RPMI medium was added to the cuvette. The experiment was allowed to run for a further 1500 seconds. Treatments consisted of $\mathrm{CB}$ or UfCB at $1 \mathrm{mg} / \mathrm{ml}$ (untreated or treated with desferal) to give a final concentration of $66 \mu \mathrm{g}$ particles $/ 1.5 \mathrm{ml}$ medium, particle leachates diluted 1:10 in medium (to give the equivalent of $1 \mathrm{mg}$ particles), or medium alone.

After the particle/leachate treatment, $7.5 \mu \mathrm{l}$ $20 \mu \mathrm{M}$ thapsigargin (Sigma) in DMSO was added to the cuvette and the experiment continued for a further 500 seconds. Twenty microlitres of $5 \%$ Triton solution was added to the cuvette to lyse the cells to give the maximum fluorescence ( $\mathrm{Rmax}$ ) and the experiment was continued for 500 seconds. To give the minimum fluorescence value (Rmin), $15 \mu \mathrm{l}$ $0.5 \mathrm{M}$ ethylene glycol tetraacetic acid (EGTA) in $3 \mathrm{M}$ Tris buffer was added to the cuvette. The experiment was ended after a further 500 seconds. The ratio of the fluorescence measurements at excitation wavelengths of 340 and $380 \mathrm{~nm}$ were converted to calcium concentration values by the method of Grynkiewicz et $a l .^{18}$

DATA ANALYSIS

Data from all experiments were analysed with analysis of variance (ANOVA) with the Tukey multiple comparison test.

\section{Results}

IN VIVO MODEL OF LUNG INFLAMMATION Particle instillation

The effect of instillation of $500 \mu \mathrm{g}$ UfCB or CB with or without desferal treatment on neutrophil (PMN) recruitment 24 hours after instillation into the lung is shown in figure 1 . The data show that after 24 hours of exposure to $500 \mu \mathrm{g}$ particles there was a significant influx of PMNs only for UfCB compared with CB. Treatment with CB produced the same level of inflammation as the control group. Treating the particles with desferal before instillation produced no difference in PMN recruitment compared with the untreated particles. The mean number of PMNs increased about eightfold after treatment with UfCB or UfCB/desferal compared with the control group.

The LDH activity in BAL from particle treated rats is shown in figure 2. There was no significant difference in $\mathrm{LDH}$ concentrations between control animals and CB treatment.

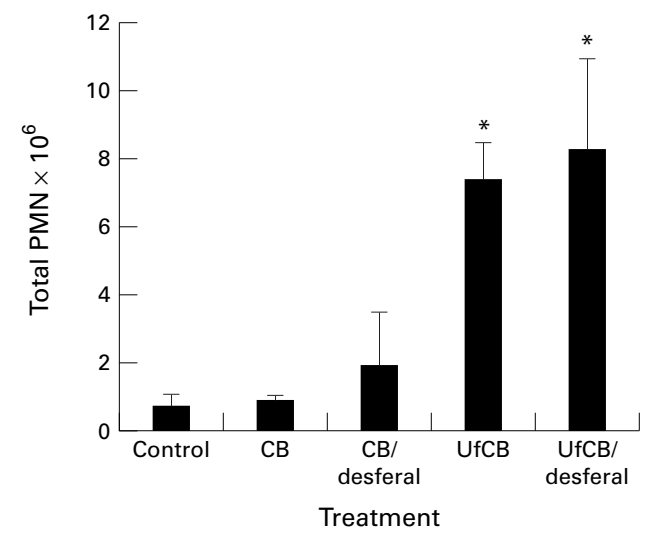

Figure 1 Neutrophil (PMN) recruitment in the lung 24 hours after instillation of $500 \mu \mathrm{g} C B$ or UfCB with or without treatment of particles with desferal. Data are expressed as the mean (SEM) total PMN in BAL from three rats per treatment. $\left({ }^{\star} p<0.05 C B v U f C B\right)$. 


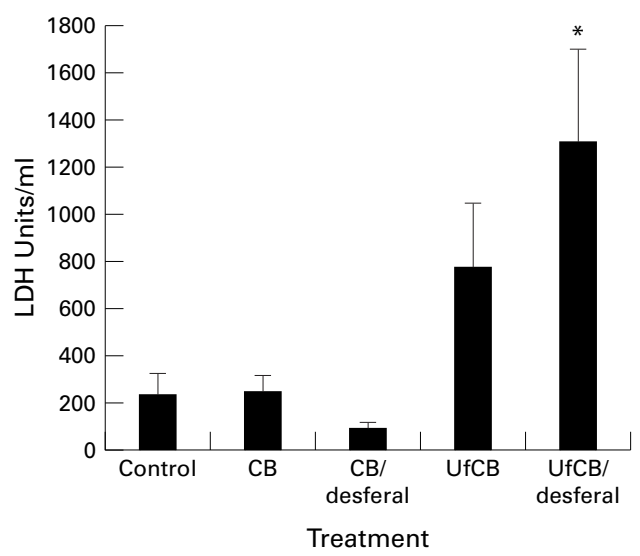

Figure 2 LDH activity in BAL 24 hours after instillation of $500 \mu \mathrm{g} \mathrm{CB}$ or UfCB with or without treatment of particles with desferal. Data are expressed as the mean (SEM) LDH units in BAL from three rats per treatment. $\left({ }^{\star} p<0.05\right.$ Control $v$ desferal treated UfCB).

Table 1. Total neutrophils in BAL, 24 hours after instillation of $0.5 \mathrm{ml}$ leachate, equivalent to a mass of $1 \mathrm{mg}$ $C B$ or UfCB prepared in saline or citrate buffer

\begin{tabular}{llllll}
\hline & \multicolumn{2}{l}{ Saline leachate } & & \multicolumn{2}{l}{ Citrate leachate } \\
\cline { 2 - 3 } \cline { 5 - 6 } Treatment & $\begin{array}{l}\text { Total PMN } \\
\times 10^{6}\end{array}$ & SEM & & $\begin{array}{l}\text { Total PMN } \\
\times 10^{6}\end{array}$ & SEM \\
\hline Control & 0.13 & 0.06 & & 0.13 & 0.06 \\
CB & 0.12 & 0.02 & & 0.13 & 0.07 \\
UfCB & 0.12 & 0.04 & & 0.19 & 0.09 \\
\hline
\end{tabular}

The data are the mean (SEM) of cell counts from six rats for the saline treatment, and three rats for the citrate treatment

The UfCB treatment produced an increase in LDH activity on average 769 Units $/ \mathrm{ml} \mathrm{com-}$ pared with 228 Units/ml for the controls, however, this increase was not significant $(p>0.05)$. Desferal treatment of UfCB particles produced more LDH release than untreated particles and this effect was significantly different from the controls $(\mathrm{p}<0.05)$.

\section{Instillation of particle leachates}

Leachates were prepared in both saline and mild citrate buffer. Citrate buffer was used as it is a mild chelator that would extract iron more readily from the particles. Instillation of either a saline or citrate leachate of $\mathrm{CB}$ or UfCB obtained from a mass of $1 \mathrm{mg}$ particles produced no significant inflammation in the rat lung. Leachates from both particle types prepared in either saline or citrate buffer produced a similar number of PMNs in the BAL as the control, as shown in table 1 .

IRON CONTENT OF LEACHATES

We attempted to measure the transition metal content of the leachates with desferal, but this was below the detection limits of the system,

Table 2 Transition metal content of $C B$ and UfCB particles leached into saline or citrate buffer

\begin{tabular}{|c|c|c|c|c|c|c|}
\hline & \multicolumn{6}{|c|}{ Final concentration (ng transition metal/mg particles) } \\
\hline & $\overline{F e}$ & $C u$ & $\mathrm{Cr}$ & $\mathrm{Ni}$ & Co & $Z n$ \\
\hline \multicolumn{7}{|c|}{ Elemental analysis of particles: } \\
\hline CB Saline & ND & 80 & ND & 85 & ND & 35 \\
\hline CB Citrate & 50 & 185 & ND & 35 & ND & 30 \\
\hline UfCB Saline & ND & 55 & ND & 105 & ND & 90 \\
\hline UfCB Citrate & 100 & 30 & 40 & 210 & ND & 25 \\
\hline
\end{tabular}

which was $15 \mathrm{nmol} / \mathrm{ml}$. As we used $1 \mathrm{mg} / \mathrm{ml}$ we can conclude that this was less than $15 \mathrm{nmol}$ of transition metal per mg particulate.

TRANSITION METAL ANALYSIS OF PARTICLE

LEACHATES

Measurement of the transition metal content of particles with ICP-MS prepared in either saline or citrate buffer showed that there was no detectable iron in leachates of CB or UfCB in saline treated particles (table 2). Leaching into citrate, however, yielded detectable iron for both particle types, twice the amount was present in UfCB leachates than CB leachates (50 ng/mg particles for CB; $100 \mathrm{ng} / \mathrm{mg}$ particles for UfCB).

\section{DEPLETION OF PROTEIN FROM BAL AND BSA} SOLUTION

Both particle types caused depletion of protein from BAL in a dose dependent manner (fig 3). This effect was most pronounced for UfCB, which depleted protein by $98 \%$ at the highest concentration of particles. The CB depleted protein in a similar manner, but by $45 \%$ for the highest concentration of particles $(5 \mathrm{mg} / \mathrm{ml})$. There was a significant $(\mathrm{p}<0.05)$ dose effect for UfCB particles and a significant difference between the particle types.

In keeping with the data produced with BAL, treatment of solutions of BSA as an indicator of protein with $\mathrm{CB}$ or UfCB resulted in depletion of protein in a dose dependent manner. These data are summarised in figure 4 . The reduction was more pronounced for UfCB. There was a significant $(p<0.05)$ dose effect for UfCB particles and a significant difference between the two particle types.

\section{$\mathrm{Ca}^{2+}$ HOMEOSTASIS IN MM6 CELLS EXPOSED TO} CB AND UfCB

The resting calcium concentration in MM6 cells was examined after addition of control particles and particles which had been treated with the iron chelator desferal (fig 5). For control cells, the mean (SEM) $\mathrm{Ca}^{2+}$ concentration was 68 (11.6) nM; after treatment with thapsigargin this increased to $390(63.8) \mathrm{nM}$. There was some variation in the $\mathrm{Ca}^{2+}$ concentration of UfCB treated cells after thapsigargin stimulation between experiments-the lowest value

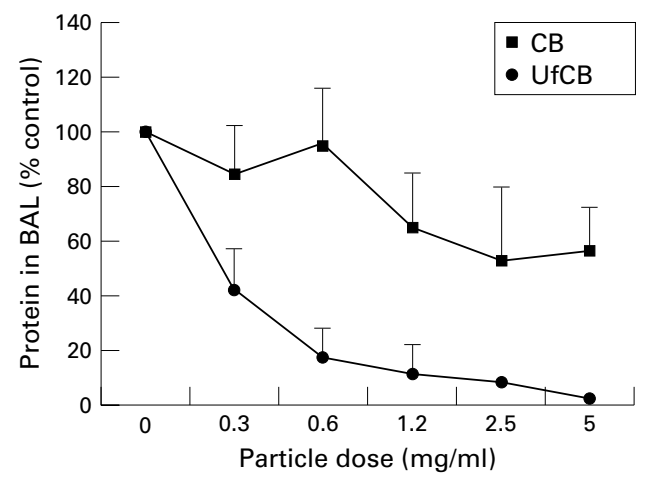

Figure 3 Protein content in $B A L$ after $C B$ or $U f C B$ treatment. Data are expressed as a percentage of the control and represent the mean (SEM) of three separate experiments. There was a significant difference between particle type and a significant effect of dose for UfCB. 


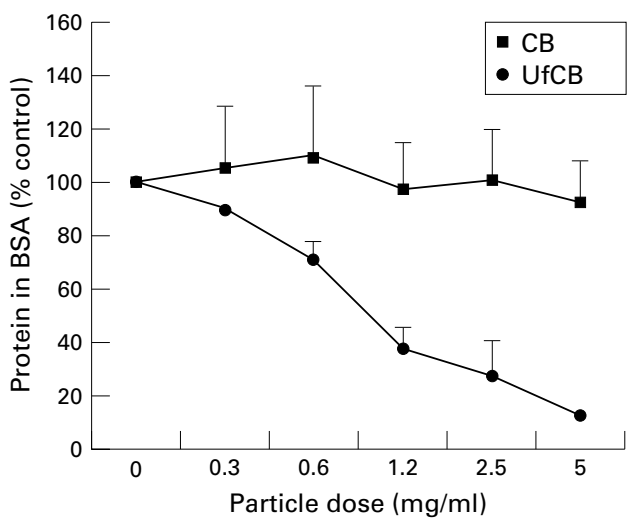

Figure 4 Protein content in a solution of BSA after $C B$ or UfCB treatment. Data are expressed as a percentage of the control and represent the mean (SEM) of three separate experiments. There was a significant difference between particle types and a significant dose effect of UfCB.

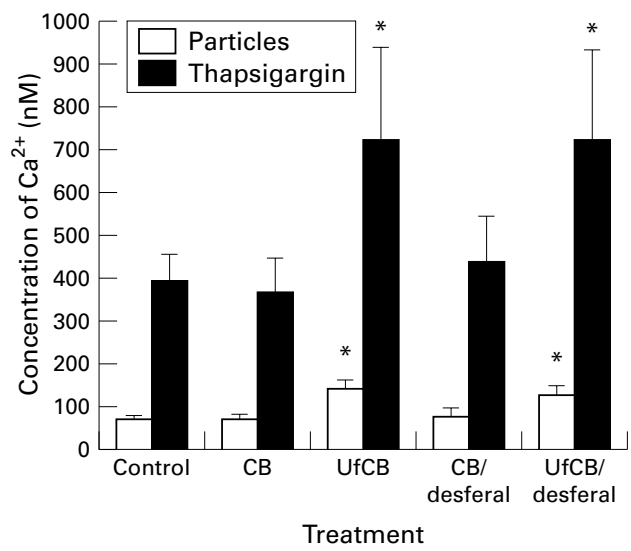

Figure 5 Cytosolic $\mathrm{Ca}^{2+}$ concentration in MM6 cells after addition of $C B$ and $U F C B$ with and without treatment with desferal and after thapsigargin stimulation. Data are expressed as the concentration of $\mathrm{Ca}^{2+}$ in $n M$ and represent the mean (SEM) of three separate experiments $(p<0.05$ $C B$ v UfCB and $C B$ plus desferal v UfCB plus desferal and after thapsigargin stimulation).

was $391.5 \mathrm{nM}$ and the highest was $1118.7 \mathrm{nM}$. Treatment with UfCB produced a significantly greater increase in cytosolic $\mathrm{Ca}^{2+}$ concentration than CB $(p<0.05)$ with particles both alone and after stimulation. Treatment of either CB or UfCB with desferal did not significantly alter the effects of either of these two particles on the resting $\mathrm{Ca}^{2+}$ concentration nor the response to thapsigargin compared with untreated particles.

Leachates of both CB and UfCB prepared in acidic or neutral $\mathrm{pH}$ citrate buffer were used to investigate the effects of potential metal contaminants from the particles on calcium homeostasis in MM6 cells. The results of these experiments are summarised in table 3 . There was an increase in the cytosolic $\mathrm{Ca}^{2+}$ concentration induced after treatment with thapsigargin

Table 3 Cytosolic $\mathrm{Ca}^{2+}$ concentration (nM) in MM6 after addition of leachate

\begin{tabular}{|c|c|c|c|c|}
\hline \multirow{2}{*}{$\begin{array}{l}\text { Leachate } \\
\text { (concentration } \mathrm{Ca}^{2+} \\
n M)\end{array}$} & \multicolumn{2}{|c|}{ Leachate added $p H$} & \multicolumn{2}{|l|}{ Thapsigargin $p H$} \\
\hline & 7.2 & 4.6 & 7.2 & 4.6 \\
\hline Control & $65.82(1.07)$ & $79.85(19.06)$ & $495.12(91.09)$ & $680.81(199.67)$ \\
\hline $\mathrm{CB}$ & 75.49 (3.09) & $88.67(22.04)$ & $445.07(119.94)$ & $663.3(208.23)$ \\
\hline UfCB & $77.6 \quad(6.18)$ & $73.68(20.36)$ & $531.57(123.23)$ & $622.9 \quad(199.79)$ \\
\hline
\end{tabular}

Data are the mean (SEM) of three separate experiments. for $\mathrm{pH} 4.6$ leachate compared with $\mathrm{pH} 7.2$ leachate although this effect was not significant. There was no significant difference in the resting cytosolic $\mathrm{Ca}^{2+}$ concentration or the response to thapsigargin when $\mathrm{CB}$ and UfCB leachates were compared.

\section{Discussion}

This study considers an important issue in the debate on the mechanism of lung injury caused by environmental particles $\left(\mathrm{PM}_{10}\right)$. The components of $\mathrm{PM}_{10}$ include fine particles that tend to be secondary in formation comprising sulphate and nitrate, and ultrafine primary particles that are often aggregated, derived from combustion, and contain a carbon core. Studies have shown that transition metals can drive the proinflammatory effect of various types of environmental particles in vivo and in vitro. ${ }^{11}$ We have shown that Edinburgh $\mathrm{PM}_{10}$ retrieved from TEOM filters can generate oxidants as shown by Fenton chemistry through the involvement of transition metals. ${ }^{13}$ We have also suggested that the ultrafine component of $\mathrm{PM}_{10}$ may mediate some of its toxicity. ${ }^{319}$ To fully understand the toxicity of $\mathrm{PM}_{10}$ it is necessary to dissect out the contribution that the components make to the total toxicity. Any ultrafine particles present could have adverse effects through transition metals associated with the surface, or ultrafine particles might have intrinsic toxicity regardless of transition metals. We used UfCB as a model ultrafine particle to find whether the increased inflammation they caused was, or was not, related to contaminating transition metals.

Toxicological studies of ultrafine $\mathrm{TiO}_{2}$ and $\mathrm{CB}^{5820}$ show that ultrafine particles with no well documented transition metal content are highly inflammogenic. This has an important bearing as filter derived particle samples are likely to be highly biased toward the transition metal effect because the metals are soluble and in general filters are soaked in saline or something similar to release the particle sample. Indeed all the biological activity of some $\mathrm{PM}_{10}$ samples is in the soluble fraction. ${ }^{21}$ At the same time such filter samples may bias against the effects of ultrafine particles as these are likely to be highly adhesive and poorly retrieved from the filter matrix compared with soluble components. Our instillation data show that UfCB particles produced a significant neutrophil influx into the rat lungs compared with an equivalent mass of $\mathrm{CB}$, as previously reported for a $125 \mu \mathrm{g}$ dose. ${ }^{1020}$

We used desferal as a chelator to study the role of transition metals and envisaged that there might be two effects of desferal on transition metals associated with particles. (1) Releasable or mobilisable transition metals would be drawn out of the particles and chelated. (2) Any transition metal that could not freely diffuse from the particle would be chelated on the particle. In either case, desferal treatment should show whether transition metals are involved in the proinflammatory effect of UfCB.

Earlier desferal treatment caused no significant effect on the inflammation caused by 
UfCB; CB had no significant inflammatory effect. As a measure of direct particle toxicity, $\mathrm{LDH}$ activity was measured in BAL after instillation. The only significant increase in $\mathrm{LDH}$ was caused by UfCB/desferal, but there was no significant difference between UfCB/ desferal and UfCB with large variance in both. Therefore we place no biological significance on the difference between UfCB/desferal and UfCB and take it to be a statistical anomaly. The epithelium of the lung becomes more permeable during inflammation but we were unable to find any evidence of increased BAL protein as an indicator of epithelial permeability after UfCB or CB instillation (data not shown).

Reactive oxygen species have been strongly implicated in mediating the inflammation from ultrafine particles. ${ }^{22}$ The transition metal iron is important in redox cycling necessary to produce oxidants through Fenton chemistry and it has previously been shown, with a plasmid scission assay, that there is greater free radical activity associated with UfCB than with the same mass of $\mathrm{CB} .^{22}$ However, we were unable to show any iron (III) in leachates of UfCB or $\mathrm{CB}$, prepared in a neutral or acidic buffer when we used the desferal assay to measure iron. Iron was detectable in citrate leachates of both $\mathrm{CB}$ and UfCB with the ICP-MS method of iron detection. This is in keeping with the very low concentrations (ng/10 mg particles) of transition metal we reported previously in acid digests of $\mathrm{CB}$ and UfCB. ${ }^{10}$ When particle leachates prepared in citrate or saline were instilled into the rat lung, no inflammation was evident, suggesting that soluble factors or transition metals from the particles were not responsible for the lung inflammation found with particles alone.

Studies with carbon black particles at the cellular level have shown that UfCB but not CB decreases metabolic processes in epithelial cells through an oxidative stress mechanism. ${ }^{22}$ Stone et al went on to describe the effects of $\mathrm{CB}$ and UfCB on calcium homeostasis in MM6 cells. ${ }^{14}$ The UfCB, but not CB, stimulated the entry of extracellular calcium and treatment with thapsigargin further increased the cytosolic calcium ion concentration compared with the controls or CB. In resting non-stimulated cells, calcium ions are sequestered into the endoplasmic reticulum, and plasma membrane $\mathrm{Ca}^{2+}-$ ATPases maintain a low cytosolic calcium ion concentration which allows $\mathrm{Ca}^{2+}$ to act as an effective intracellular signalling molecule. Thus activation of transcription factors after exposure to ultrafine particles may be mediated in part by changes in calcium homeostasis and ultimately lead to the increased expression of proinflammatory genes. We have confirmed here the findings of Stone et $a l^{14}$ that UfCB increased the resting cytosolic $\mathrm{Ca}^{2+}$ concentration and the size of the calcium response to thapsigargin was explained as an increase in the calcium current $\left(\mathrm{I}_{\mathrm{CRAC}}\right)$ activated by calcium release. In the present study, we set out to determine the role of transition metals in this phenomenon and we have extended the experiment to include $\mathrm{CB}$ and UfCB which had been treated with desferal and included leachates of $\mathrm{CB}$ and UfCB. Pretreated CB and UfCB had a similar effect to the untreated particles in the calcium experiments and leachates had no effect, suggesting that an effect mediated by iron or other soluble factors was not responsible for the enhanced calcium influx induced by UfCB.

In the absence of a clear role for transition metals in the inflammatory effects of UfCB we may look to the large particle number or surface area. Depletion of protein from BAL and solutions of BSA suggested that protein may be adsorbed on to the UfCB particle surface to a considerable extent. This may have an effect on epithelial cells by changing osmotic potential or changing the local conditions that may stress cells. The evidence of increased protein-surface interaction also raises the question of a role for complement. The alternative pathway of complement is activated when $\mathrm{C} 3$ binds to surfaces and this has been shown for asbestos and other particles. ${ }^{23}{ }^{24}$ The ability to bind protein has been related to the ability to activate complement. ${ }^{23}$ The role of complement in the effect of ultrafine particles warrants further research.

It has been suggested by Oberdoster et $a l,{ }^{5}$ that animals exposed to low concentrations of lipopolysaccharide (LPS) may become primed and on subsequent exposure to ultrafine particles may elicit an enhanced inflammatory response. This observation may help to explain why some people with underlying lung inflammation, such as asthma and chronic obstructive pulmonary disease, are susceptible to the adverse effects of particles. The calcium data presented here and reported previously ${ }^{14}$ suggest that ultrafine particles may prime lung cells at the $\mathrm{Ca}^{2+}$ level through a mechanism not mediated by metal. This may result in enhanced inflammatory effects on subsequent exposure to proinflammatory cytokines stimulated by microbes or some other concomitant exposure to a pollutant. The converse may also be true-that pre-exposure to other pollutants or infection may prime lung cells to be hyperreactive to ultrafine particles, in terms of release of a proinflammatory mediator. The surface area or particle number of the UfCB provides the most likely explanation for the difference in inflammogenicity between UfCB and $\mathrm{CB}$, and the UfCB could adsorb far more protein from lung lining fluid than the CB.

In conclusion our data show that, for one type of model ultrafine particle, the increased inflammation that it causes cannot be explained by transition metals nor other soluble factors released from UfCB. The study points out that ultrafine particles and transition metals may have independent proinflammatory effects in $\mathrm{PM}_{10}$. However, more studies on the association between transition metals and ultrafine particles in actual $\mathrm{PM}_{10}$ samples are required to fully elucidate the relative roles. Such studies are difficult to achieve but will be necessary to fully unravel the relative toxic potency of the components of the $\mathrm{PM}_{10}$ "cocktail”. 
We acknowledge the assistance of the British Lung Foundation and the Medical Research Council. KD is the Transco British
Lung Foundation Fellow in Air Pollution and Respiratory Lung Foun.

1 MacNee W, Donaldson K. Particulate air pollution: MacNee W, Donaldson K. Particulate air pollution:
injurious and protective mechanisms in the lungs. In: ST
Holgate, JM Samet, HS Koren, et al, eds. Air pollution and Holgate, JM Samet, HS Koren, et al, eds. Air poll
health. London: Academic Press, 1999:653-72.

2 Donaldson K, Li XY, MacNee W. Ultrafine (nanometer) Donaldson K, Li XY, MacNee W. Ultrafine (nanometer)
particle-mediated lung injury. F Aerosol Sci 1998;29:553particle-
60 .

3 Seaton A, MacNee W, Donaldson K, et al. Particulate air pollution and acute health effects. Lancet 1995;345:176-8.

4 Ferin J, Oberdoster G, Penney DP. Pulmonary retention of ultrafine and fine particles in rats. Am 7 Respir Cell Mol Biol 1992;6:535-42.

5 Oberdorster G, Ferin J, Lehnert BE. Correlation between particle-size, in-vivo particle persistence, and lung injury. Environ Health Perspect 1994;102(suppl 5):173-9.

6 Nikula KJ, Snipes MB, Barr EB, et al. Comparative pulmonary toxicities and carcinogenicities of chronically inhaled diesel exhaust and carbon-black in F344 rats. Fundam Appl Toxicol 1995;25:80-94.

7 Dasenbrock C, Peters L, Creutzenberg O, et al. The carcinogenic potency of carbon particles with and without carcinogenic potency of carbon particles with and without PAHs after repeated intratract

8 Driscoll KE, Carter JM, Howard BW, et al. Pulmonary inflammatory, chemokine, and mutagenic responses in rats after subchronic inhalation of carbon-black. Toxicol App Pharmacol 1996;136:372-80.

9 Mauderly JL. Usefulness of animal-models for predicting human responses to long term inhalation of particles. Chest 1996;109(suppl 3):65S-68S

$10 \mathrm{Li}$ XY, Brown D, Smith S, et al. Inflammatory responses following intratracheal instillation of fine and ultrafine carbon black in rats. Inhal Toxicol 1999;11:709-31.

11 Dreher KL, Jaskot RH, Lehmann JR, et al. Soluble transition metals mediate residual oil fly ash induced acute lung injury. $\mathcal{F}$ Toxicol Environ Health 1997;50:285-305.

12 Kennedy T, Ghio AJ, Reed W, et al. Copper-dependent

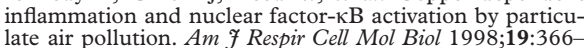
78 .
13 Gilmour PS, Brown DM, Lindsay TG, et al. Adverse health effects of $\mathrm{PM}_{10}$ particles: involvement of iron in generation of hydroxyl radical. Occup Environ Med 1996;53:817-22.

14 Stone V, MacNee W, Faux S, et al. Oxidative stress in epithelial cells exposed to ultrafine carbon black in vitro. Eur Respir f 2000;15:297-303.

15 Dolmetsch RE, Xu K, Lewis RS. Calcium oscillations increase the efficiency and specificity of gene expression. Nature 1998;392:933-6.

16 Faux SP, Michelangeli F, Levy LS. Calcium chelator quin-2 prevents crocidolite-induced DNA strand breakage in human white blood cells. Mutat Res 1994;311:209-15.

$17 \mathrm{Lim}$ Y, Kim SH, Cho YJ, et al. Silica-induced oxygen radical generation in alveolar macrophages. Industrial Health 1997; 35:380-7.

18 Grynkiewicz G, Poenie M, Tsien RY. A new generation of $\mathrm{Ca}^{2+}$ indicators with greatly improved fluorescent properties. F Biol Chem 1985;260:3440-50.

19 Donaldson K, MacNee W. The mechanism of lung injury caused by $\mathrm{PM}_{10}$. Air pollution and health. In: Hester RE, Harrison RM, eds. Issues in environmental science and technology. Cambridge, UK: The Royal Society of Chemistry, 1998:10.

$20 \mathrm{Li}$ XY, Gilmour PS, Donaldson K, et al. Free radical activity and pro-inflammatory effects of particulate air pollution $\left(\mathrm{PM}_{10}\right)$ in vivo and in vitro. Thorax 1996;51:1216-22.

21 Costa DL, Dreher KL. Bioavailable transition metals in particulate matter mediate cardiopulmonary injury in healthy and compromised animal models. Environ Health Perspect 1997;105(suppl 5):1053-60.

22 Stone V, Shaw J, Brown DM, et al. The role of oxidative stress in the prolonged inhibitory effect of ultrafine carbon black on epithelial cell function. Toxicology in Vitro 1998;12 649-59.

23 Wilson MR, Gaumer HR, Salvaggio JE. Activation of the alternative complement pathway and generation of chemotactic factors by asbestos. F Allergy Clin Immunol 1997;60 218-22.

24 Governa M, Camilucci L, Amati M, et al. Woolastonite fibers in vitro generate reactive oxygen species able to lyse erythrocytes and activate the complement alternate pathway. Toxicol Sci 1998;44 32-8. 